\title{
Divisão de autoridade em Estados unitários e federais e difusão de políticas
}

\author{
Evelise Zampier da Silva ${ }^{1}$ \\ Samira Kauchakje ${ }^{2}$
}

\section{Introdução}

Internacionalmente a partir da década de 1990, e no Brasil a partir de 2010, ganham relevo na análise de políticas públicas as abordagens que tratam do trânsito de políticas de uma jurisdição para outra. Ainda que não haja consenso terminológico ou conceitual a respeito destes processos, todos os estudos tratam, de forma mais ou menos abrangente, de dinâmicas que envolvem a difusão ou a transferência de políticas ou elementos de políticas de um contexto para outro (entre esferas governamentais ou dentro delas).

Parte destes estudos se ocupa em fragmentar o processo de difusão e transferência; alguns de acordo com o framework de Dolowitz e Marsh ${ }^{3}$ (BRAY; TAYLOR; SCRAFTON, 2010; HULME, 2005; MARSDEN; STEAD, 2011), outros respondendo suas próprias questôes empíricas (COOK, 2008; JACOBS; BARNETT, 2000). Uma parcela destaca o papel dos atores envolvidos, analisando a atuação de redes de políticas, grupos de pressão, think tanks, comunidades epistêmicas, empreendedores de políticas, organizaçóes internacionais etc. (DUNLOP, 2009; GONNETT, 2012; HOCHMAN, 1988; MINTRON, 1997; SILVA, 2015). Outros fazem análises comparativas observando alteraçóes sofridas pela política no processo de difusão e transferência (BRADY; CURTIN, 2012; GOLDFINCH, 2006). Por último, há os estudos que consideram os fatores subjacentes que motivam, condicionam ou impulsionam a transferência e a difusão, concentrando-se, em sua maioria, em explicaçóes geográficas, culturais ou socioeconômicas (HOSPERS; BEUGELSDIJK, 2002; NEWBURN, 2002; WEYLAND, 2007).

Os estudos sobre transferência e difusão tendem a privilegiar o papel dos atores envolvidos e a análise do conteúdo transferido ou dos mecanismos que propiciaram o espraiamento da política (em especial a coerção, a competição, o aprendizado e a imitação), destacando a importância das ideias, das interaçóes entre atores internos ou externos à esfera governamental e o modo como estas interaçóes ocorrem, desconsiderando ou dando

1 Doutoranda em Ciência Política no Programa de Pós-Graduação em Ciência Política da Universidade Federal do Paraná (UFPR). Pesquisadora do Laboratório de Pesquisa em Política: Representação e Relaçóes Intergovernamentais (Lapre - PUCPR) e do Núcleo de Pesquisa em Relaçóes Internacionais (Nepri - UFPR).

2 Professora titular no Programa de Pós-Graduação em Gestão Urbana da Pontifícia Universidade Católica do Paraná (PUCPR) e professora colaboradora no Programa de Pós-Graduação em Ciência Política da Universidade Federal do Paraná (UFPR). Pesquisadora visitante na University of Illinois Urbana-Champaign (de julho de 2015 a 3 de janeiro de 2017) e coordenadora do Laboratório de Pesquisa em Política: Representação e Relaçóes Intergovernamentais (Lapre - PUCPR).

3 Que analisa: quem se envolve na transferência, o que é transferido, de onde as liçóes sobre políticas são retiradas, qual o grau da transferência, quais as limitaçóes ao aprendizado e o que demonstra que a transferência ocorreu. 
menos destaque ao peso dos arranjos institucionais nos processos e no resultado que será alcançado. Conforme Souza (2006, p. 17-18), a importância de se analisar políticas públicas sob a perspectiva das instituiçóes, é perceber que não só indivíduos e grupos as influenciam ou determinam, mas que regras formais e informais importam, "moldando o comportamento dos decisores".

Sob essa ótica, a influência das variáveis institucionais é um aspecto menos explorado pela pesquisa no campo. Entre os estudos que analisaram a ação dessas variáveis, podemos citar análises que consideraram a influência da variável partidária no espraiamento de políticas (CÔELHO, 2012; CÔELHO; CAVALCANTI; TURGEON, 2016; KAUCHAKJE; SILVA; PESSALI, 2014; WAMPLER, 2008) e estudos que consideraram a divisáo vertical de poderes entre governo central e unidades subcentrais (GILARDI; FUGLISTER, 2008; GRAY, 1973; MCCANN; SHIPAN; VOLDEN, 2015; SHIPAN; VOLDEN, 2006; WALKER, 1969). Apesar dessas pesquisas, consideramos necessário reforçar ainda mais o acúmulo de pesquisas empíricas que isolem a variável institucional para exame. Nosso artigo e pesquisa em desenvolvimento pretendem participar desse esforço.

Em se tratando de sistemas políticos federais, em tese, uma de suas características distintivas é a capacidade de inovaçâo das unidades subcentrais, em razão de sua autonomia administrativa, legislativa e fiscal em cenários de descentralização das políticas públicas. Governos locais teriam capacidades, competências e recursos próprios que facilitariam implementar políticas independentemente da concordância do governo central. Tais fatores permitiriam a "experimentação institucional" (LIJPHART, 2012, p. 175). De modo contrário, também em uma perspectiva teórica, Estados unitários teriam maior uniformidade de políticas públicas, e mesmo havendo divisóes administrativas locais, estas teriam capacidade decisória limitada para inovar, tendo em vista o maior poder dirigente do governo central. Vale lembrar, como discutiremos adiante, que processos de federalização, descentralização e devolução têm demonstrado o enfraquecimento da distinção entre Estados unitários e federais.

O objetivo do artigo é verificar, de forma sistemática e integrativa, como a difusão, a transferência e o aprendizado de políticas ocorrem dentro de arranjos federais e unitários. Observamos se a divisão territorial de poderes entre governo central e unidades subcentrais repercute no espraiamento de políticas, ou se, em sentido contrário, a difusão, a transferência ou o aprendizado de políticas entre os entes constitutivos interferem nas relaçóes intergovernamentais. Procuramos analisar se há diferenças de um cenário para outro que podem ser atribuídas a incentivos decorrentes das relaçôes intergovernamentais existentes, se podem ser identificados padróes ou características determinantes atreladas a cada modelo, ou se os processos ocorrem de maneira similar, independentemente dos arranjos internos entre governo central e unidades subcentrais seguirem a forma federal ou unitária, centralizada ou descentralizada.

Destacamos que a discussão teórica e a análise empírica aqui apresentada integram pesquisa em andamento ${ }^{4} \mathrm{e}$, como tal, trazem resultados preliminares, que sinalizam as relaçōes entre a estrutura vertical/territorial de divisão de poder de um determinado Estado (unitário/federal, centralizado/descentralizado) e os processos de transferência e difusão de políticas públicas que nele ocorrem. Nesse estágio da pesquisa não temos a pretensão de apresentar respostas definitivas e conclusivas, mas demonstrar que conjugar difusão e

$4 \quad \mathrm{O}$ artigo discute resultados preliminares de pesquisa que integra a tese de doutorado de uma das autoras. 
transferência e relaçóes intergovernamentais é uma agenda de pesquisa promissora, afinal ambientes de compartilhamento de funçôes executivas, administrativas, legislativas e tributárias entre unidades escalonadas verticalmente em uma mesma estrutura política são propícios ao trânsito de inovaçóes entre jurisdiçōes (BAYBECK, BERRY; SIEGEL, 2011; BERRY; BERRY 1990; MINTROM, 1997; SUGIYAMA, 2008; VOLDEN, 2006).

$\mathrm{O}$ artigo está estruturado em seçóes que tratam dos conceitos de transferência e difusão de políticas, da divisão de autoridade e das relaçóes intergovernamentais em sistemas políticos unitários e federados, e dos elementos e características distintivas dos processos de transferência e difusão de políticas públicas em Estados unitários e federais, centralizados e descentralizados.

\section{Transferência e difusão de políticas públicas}

Entenderemos políticas públicas a partir das definições de Lasswell e Kaplan (1950), Dye (1984) e Lowi (1985), isto é, como produto da ação dos governos que materializa preferências, influências, prioridades, contingências e obrigações, provocando efeitos na sociedade. $\mathrm{O}$ modo como estes elementos serão ponderados na formulação e implementação de políticas públicas relaciona-se às condiçôes de autonomia, à capacidade decisória e à habilidade no cumprimento de metas do tomador de decisão (EVANS; RUESCHEMEYER; SKOCPOL, 1985, p. 9; PRZEWORSKI, 1995).

Ao formular políticas, os decisores estão sob a influência de seus valores, conhecimentos e interesses, podendo interagir de alguma forma com grupos de interesse, movimentos sociais, partidos e outros atores que circulam dentro e fora da burocracia governamental (SILVA, 2015, p. 30). Na formulaçáo de políticas podem incidir também informaçôes sobre o conteúdo de políticas já existentes em outras jurisdiçôes, o que tem o potencial de provocar um processo de aprendizado (policy learning, lesson drawing), ou de recomendaçáo, por órgáos ou especialistas nacionais ou internacionais, em um processo de transferência ou difusão de políticas públicas que, em estágios posteriores, pode levar à convergência ou ao isomorfismo.

A literatura diverge na definição conceitual das categorias de modelagem de políticas públicas $^{5}$ - "aprendizado", "difusão", "transferência", "convergência", "isomorfismo". Adotamos aqui o entendimento de David Dolowitz e David Marsh, utilizado na maioria dos estudos sobre essas diferentes abordagens e que abarca a ideia geral de transferência como um processo

pelo qual o conhecimento sobre políticas, arranjos administrativos, instituiçôes e ideias em um sistema político (passado ou presente) é usado no desenvolvimento de políticas, arranjos administrativos, instituiçōes e ideias em outro sistema político. (DOLOWITZ; MARSH, 2000, p. 5) 7

5 Skocpol e Amenta (1986, p. 147) falam da "modelagem cultural internacional" pela qual políticas sociais, por incentivo de organizaçóes como ONU e OIT se espraiam, gerando um padrão mesmo entre naçóes com diferentes características internas.

6 Esclarecemos que, para fins deste artigo, nos interessam, especificamente, os casos de aprendizado, transferência e difusão de políticas, por melhor retratarem o trânsito parcial ou integral de uma política preexistente de um contexto para o outro. Excluímos de nossa análise os casos de a convergência, pois esta se aplica à adoção sistemática e continuada de uma mesma política por diferentes jurisdiçóes durante um período continuado de tempo, e o isomorfismo, por estar vinculado mais à análise de aspectos organizacionais da Administraçáo Pública.

7 Tradução propria. No original: "the process by which knowledge about policies, administrative arrangements, institutions and ideas in one political system (past or present) is used in the development of policies, administrative arrangements, institutions and ideas in another political system." (DOLOWITZ; MARSH, 2000, p. 5) 
As transferências seriam dinâmicas pelas quais o conteúdo integral ou parcial de uma política é retirado de uma jurisdição ou órgão governamental e replicado em contexto diverso, dinâmicas essas marcadas pelo trânsito de inovaçóes políticas, ou seja, programas e políticas novas para o adotante, independentemente do tempo que já existem no seu local de origem (WALKER, 1969 , p. 881). A difusão, mais especificamente, remete à ideia de contágio (STONE, 2000, p. 4) e explica-se porque na busca por soluçóes políticas haveria uma tendência a "olhar para o exterior" à procura de respostas formuladas por outras jurisdiçóes para problemas similares (BENNETT, 1991, p. 200).

Cabe uma diferenciação entre os componentes de uma política que são objeto de transferência ou difusão. Componentes hard são o conteúdo, as ferramentas e os arranjos institucionais, e componentes soft são as metas, as ideologias, as normas, os conceitos e os princípios (DOLOWITZ; MARSH, 2000; EVANS; DAVIES, 1999; STONE, 2000). Nem todos os componentes de uma política são necessariamente transladados de uma jurisdição à outra, podendo ocorrer "filtragem" e adaptação ao contexto adotante (ACHARYA, 2004; KAUCHAKJE; SILVA; PESSALI, 2014).

A transferência de políticas pode ser voluntária ou coercitiva, e o grau de transferência dependerá do tipo da política, do momento em que a transferência ocorre no ciclo da política, dos atores envolvidos e das motivaçóes que os levam a se engajar nesses processos. Além disso, um mesmo caso pode envolver aspectos voluntários e coercitivos (DOLOWITZ; MARSH, 2000, p. 13, p. 15-17) ou pode ser inicialmente transferido com maior carga de coerção, que depois se flexibiliza.

Por que ocorre difusão ou transferência de políticas? Os primeiros motivos para buscar soluçóes externas são a incerteza do tomador de decisão (DIMAGGIO; POWELL,
1983, p. 154; HAAS, 1992, p. 2; ROGERS, 2003, p. 6) e sua racionalidade limitada (WEYLAND, 2007, p. 32). Também explicam a busca por modelos externos: busca de poder político ou adequação econômica e social (DIMAGGIO; POWELL, 1983, p. 150); "propensão para inovar" (BERRY; BERRY, 1990); inclusão de temática na agenda, resposta a pressóes políticas, conformidade com um modelo exemplar, procura de melhores políticas (BENNET, 1991, p. 33); estratégia política (RADAELLI, 2000, p. 28); resposta a pressóes políticas para cumprir legislação internacional, competição, conformidade (HOLZINGER; KNILL, 2005, p. 779-793); e busca de legitimidade (BENNETT, 1991; DIMAGGIO; POWELL, 1983; HOLZINGER; KNILL, 2005).

Além das causas, haveria fatores facilitadores do espraiamento de políticas, como proximidade física, identidade cultural ou ideológica, e aspectos econômicos e sociais, como hierarquia ou interdependência entre os polos emissor e receptor da política. Outros facilitadores seriam padróes de desenvolvimento similares que levariam a problemas comuns e respostas análogas (BENNETT, 1991, p. 31-32), a interação em canais comuns de comunicação favorecendo a adoção sequencial de uma inovação (BENNETT, 1991, p. 31; WALKER, 1969, p. 884), e o cosmopolitismo dos adotantes (WALKER, 1969, p. 884).

Interessa-nos também examinar a relação entre divisão vertical ou territorial de poder e modelagem de políticas, visto que, conforme a literatura mencionada, a hierarquia ou a interdependência entre as unidades e a existência de canais comuns de comunicação entre governo central e unidades subcentrais - ou entre unidades subcentrais - são elementos facilitadores da difusão ou transferência de políticas. Por isso, no próximo tópico discutiremos a repartição e centralização de autoridade, bem como 
as relaçôes intergovernamentais e seus efeitos no desenho de sistemas políticos unitários, federais ou híbridos para depois apontarmos relaçóes que essas estruturas podem ter em processos de transferência e difusão e aprendizado de políticas públicas.

\section{Divisão de poder e relações intergovernamentais}

Primeiramente esclarecemos que analisamos a divisáo de poder sob a perspectiva da estrutura de divisão territorial ou vertical entre unidades de um sistema político (central e subcentrais), no contexto das regras formais que dividem competências entre ordens ou níveis de governo, concentrando poderes no ente central e/ou concedendo maior ou menor autonomia às unidades subnacionais. Outra acepção relacionada é a de poder decisional mais ou menos centralizado no âmbito de políticas públicas, considerando a "distinção conceitual entre responsabilidade pela execução de políticas públicas (policy-making) e a autoridade para tomar decisôes sobre estas mesmas políticas (policy decision-making)" (ARRETCHE, 2010, p. 596). Nesses dois sentidos recorremos à concepção de divisão territorial que supera a rigidez da dicotomia teórica entre arranjos federais ou unitários, entendendo que, ainda que cada país estruture constitucionalmente suas relaçôes intergovernamentais de uma ou outra forma, a operacionalização destas relações frequentemente é pautada por gradaçôes de federalismo, mesmo em Estados unitários (WATTS, 2013, p. 21).

Assim, a ideia de "self-rule plus shared rule" (ELAZAR, 1987, p. 12) - garantindo a coexistência de competências próprias e competências compartilhadas entre governo central e unidades subcentrais - que, teoricamente, definiria os Estados que adotam o sistema federal, não os distingue, empiricamente dos Estados que adotam o arranjo unitário.
Medidas de descentralização de poderes ou funçôes (políticas, administrativas, tributárias) - que asseguram que uma parcela de poder seja exercida em nível regional/local podem ser identificadas em diversos países unitários, como Itália, Espanha e Dinamarca. Decorrentes de acordos formais que garantem a integridade das unidades, esses mecanismos que aproximam Estados unitários de arranjos federativos são restritos a questóes estabelecidas pelas autoridades centrais, sendo sujeitos à supervisão, restrição e retirada (ELAZAR, 1987, p. 12, 46, 49).

Assim, tanto em Estados unitários como em Estados federais pode haver maior ou menor centralização de poder no governo central. Segundo Arretche (2010), uma maior centralização limita a autonomia subnacional, relegando suas decisóes à capacidade executória (caso das políticas de educação, saúde e assistência social no Brasil), enquanto uma menor centralizaçáo permite que a unidade subnacional tenha autonomia decisória para formulaçáo e para execução (no Brasil, infraestrutura urbana, habitação, transporte público).

Watts (2005, p. 322) defende que o termo "descentralização" pressupóe hierarquia, com uma repartição de poder originária do centro em direção às partes, sendo mais aplicável aos Estados unitários. Para ele, nas federações, o termo correto seria "não-centralizaçâo". Em outro texto, Watts destaca que devemos atentar para dois aspectos: o alcance da jurisdição e o grau de autonomia das unidades constituintes. O último é medido pela liberdade de atuação, sem o risco de revogaçáo de poderes pelo governo central, característica que efetivamente diferenciaria os sistemas unitários dos federais (WATTS, 2013, p. 31).

Ao tratar da temática, Rodden (2005) destaca que a primeira frustração dos estudos sobre divisão de poder entre governo central e unidades subcentrais foi perceber que a diferença entre Estados unitários e federais não 
se dá pela descentralização de autoridade em termos genéricos, mas principalmente pela descentralização da autoridade fiscal, e depois pela descentralização da autoridade política e da gestão de políticas. Para nós, interessa a descentralizaçáo na gestáo de políticas, que pode ocorrer, em maior ou menor grau, tanto em Estados unitários como em Estados federais. A descentralização de políticas refere-se à mudança de uma situação "de completo controle do governo central para a de um envolvimento entre o centro e uma ou mais unidades subnacionais" (RODDEN, 2005, p. 15).

A despeito de toda essa discussão, frequentemente os modelos unitário e federal são diferenciados pela centralizaçẫo do poder, associando-se, diretamente e de maneira simplista, o federalismo à descentralizaçáo, e os Estados unitários à centralização. Lijphart (2012) afirma que centralização e descentralização são questôes de grau, e disso concluímos que a categorização dos Estados não pode ser binária, mas que segue um continuum com Estados federais e descentralizados, como Canadá e Estados Unidos; federais e centralizados, como Áustria e Índia; semifederais, como Holanda e Espanha; unitários e descentralizados, como Dinamarca, Noruega e Suécia; e unitários e centralizados, como Grécia, Portugal e Uruguai (LIJPHART 2012, p. 177 e ss.). Watts (2005, p. 322-349) oferece outra classificação, considerando Suíça, Canadá e Bélgica como os mais descentralizados; Índia na sequência; Estados Unidos e Austrália no início fortemente não-descentralizados teriam aumentado o poder dos governos centrais; Alemanha, moderada; Brasil, Nigéria e México, centralizados. Além disso, mesmo nas federaçóes a descentralizaçáo não é necessariamente uniforme, podendo atingir algumas áreas e não outras; a Suíça é um exemplo de centralização no âmbito legislativo, sendo menos centralizada nas esferas administrativa e financeira (WATTS, 2005, p. 322-349).
O caso brasileiro exige que nos aprofundemos uma camada a mais na análise, observando a distinção entre demos constraining e demos enabling (STEPAN, 1999), isto é, a capacidade que as unidades subnacionais têm de restringir o poder central através de pontos de veto. Para Stepan, o Brasil seria um caso extremo de demos constraining. Ames (2003) vai no mesmo sentido, afirmando que a estrutura institucional brasileira concede aos Estados da federaçáo poderes decisivos na manutenção do status quo. Porém, Marta Arretche (2013) alega que o sistema brasileiro é desenhado de modo a impedir que grupos minoritários bloqueiem a vontade da maioria. Desta forma, segundo a autora, combinadas as instituiçóes do federalismo brasileiro, o amplo campo de competências legislativas da União, o predomínio de interesses partidários e a não representação de interesses territoriais nas casas legislativas, temos um governo central altamente fortalecido, o que, ao contrário dos autores antes citados, situa o Brasil como um caso de Estado federal centralizado.

Em uma federação, duas condiçóes institucionais contribuem significativamente para o fortalecimento do governo central: amplos poderes de formulação de políticas (amplo alcance e amplitude jurisdicional) e reduçáo das plataformas de veto na aprovação de leis de seu interesse. A primeira autoriza o governo central a ter iniciativa legislativa na maioria das políticas, enquanto a segunda requer apenas pluralidades - e náo supermaiorias - para aprovar leis que o favorecem (ARRETCHE, 2013). No caso brasileiro, ambas as características estáo presentes, ou seja, as instituiçóes políticas brasileiras não constrangem as mudanças, mas as tornam possíveis, fortalecendo o governo central.

Superada a discussão centralização versus descentralização, o traço distintivo entre Estados constituídos sob o sistema unitário e Estados formados sob o sistema federal seria a 
fonte de poder e autoridade, que nos modelos unitários está situada unicamente no governo central. Nessa perspectiva, o federalismo seria, segundo Lijphart (2012, p. 174), o mais típico e drástico modelo de divisão de poderes, pois os distribui entre níveis inteiros de governo. Nos Estados unitários pode haver, através de discricionariedade do governo central, algum grau de descentralização de capacidades políticas, fiscais ou administrativas em prol das unidades subcentrais, mas estas podem ser restringidas ou retiradas a qualquer momento. No modelo unitário, o governo central controla todo o aparato governamental, inclusive das unidades subcentrais, enquanto no modelo federal o governo central, além de dividir poder com as unidades subcentrais, garante que elas o exerçam efetivamente (LIJPHART, 2012, p. 175).

Da garantia constitucional de autonomia no sistema federal, que protege unidades subcentrais da retirada unilateral de poderes por parte do governo central, derivam duas características relevantes dos sistemas federativos: a rigidez constitucional e a presença de tribunais constitucionais fortes, atuando como salvaguardas do pacto federativo.

Entrando nessa seara, Lijphart (2012) elenca três principais elementos que distinguem Estados unitários de Estados federais: divisão do poder legislativo, rigidez constitucional e tribunal constitucional. Quanto à primeira característica, o contraste poder legislativo unicameral versus poder legislativo bicameral corresponderia, em termos gerais, à dicotomia unitário versus federal. Quanto à segunda e terceira características, e como já mencionado, o federalismo apresentaria mais dificuldades para que alterações na Constituição fossem promovidas, havendo forte atuação dos tribunais constitucionais; os Estados unitários, por sua vez, teriam constituiçóes mais flexíveis e tribunais constitucionais ausentes ou fracos.

Para Rodden (2005, p. 17-18), o acordo pelo qual unidades autônomas cedem autoridade ao centro, formando uma federação, prevê garantias para estas unidades, entre as quais estão: (i) uma Constituição que tutela a autonomia e a soberania das unidades, concedendo-lhes, em alguns casos, "poderes residuais"; (ii) um tribunal constitucional forte e independente; (iii) quóruns qualificados para aprovação de mudanças políticas, especialmente aquelas que alteram a distribuição de autoridade política e fiscal. Os componentes elencados por Lijphart e Rodden demonstram que, no federalismo, teríamos uma estrutura de distribuiçẫo de autoridade entre diferentes níveis de governo, baseada em um conjunto de instituiçôes próprias que asseguram distribuição e redistribuição de autoridade, ao mesmo tempo em que a soma das autoridades dos governos central e subcentral é fixa, o que preserva a unidade e estabilidade do todo (RODDEN, 2005, p. 17).

Análises mais apuradas substituem a tradicional e engessada dicotomia entre Estados unitários e federais pela ideia de Estados híbridos que, mesmo que originalmente formados sob determinado modelo, passam a combinar instituiçôes e elementos de ambas as formas, em uma abordagem funcional do federalismo (MARKS; HOOGHE; SCHAKEL, 2008; PALERMO; KÖSSLER, 2017). Nesse contexto se enquadram processos de federalização e devolução como os observados na Espanha e no Reino Unido, respectivamente. Através da federalização, acordos entre governo central e unidades subcentrais (regiōes, províncias etc.) se desenvolvem de modo a tornar presente o federalismo sem que a organização federal efetivamente exista (BALDI, 1999). Com a devolução, temos a transferência de autoridade decisória e executória para níveis não centrais, em um processo de reconfiguraçáo de autoridade nos dois polos (ONGARO, 2006, p. 9).

Watts (2013) menciona o exemplo da Espanha, que seria uma federação em tudo, menos no nome, incorporando, como a África do Sul, inúmeros elementos do federalismo em 
sua estrutura mas evitando adotar a marca "federação". Lijphart (2012) considera a Espanha o país mais difícil de ser classificado, devido à ampla autonomia de regióes como Catalunha, Galícia, País Basco. Devemos lembrar, no entanto, que os recentes acontecimentos envolvendo a tentativa de independência da Catalunha, e a consequente reação do governo central em Madri, denotam que a Espanha mantém forte a prerrogativa de retirada de poderes das unidades constituintes, o que sinaliza que as características do modelo unitário permanecem presentes.

Alguns autores chegam a afirmar que o modelo unitário está em desuso (GERRING; THACKER; MORENO, 2005), partindo da análise dos processos de descentralização, devolução e federalização. Por outro lado, há casos de Estados federais em que a descentralização não é um traço distintivo tão marcante, e onde a autoridade decisória e as principais competências concentram-se no governo central - casos de Brasil, Argentina ou Áustria.

Lijphart (2012, p. 78), tratando de 36 democracias classificadas como Estados unitários ou federais, aponta a existência de três Estados semifederais - Espanha, Holanda e Israel. Além destes, o autor acrescenta:

A categoria semifederal inclui três democracias que Robert Dahl chamou de "sociologicamente federais" (citado em Verba 1967, 126): Bélgica, Holanda e Israel. Os governos centrais desses países há muito reconhecem, fortemente subsidiam e delegam poderes a associaçóes privadas estabelecidas pelos principais grupos religiosos e ideológicos dessas sociedades com importantes funçóes semipúblicas, especialmente nos campos da educação, cultura e saúde. Como esses grupos não estão geograficamente concentrados, o federalismo sociológico se desvia do critério de Riker de que as unidades componentes de uma federação devem ser de natureza regional. $\left(\right.$ LIJPHART, 2012, p. 180) ${ }^{8}$

Dentre os modelos de Estado que adotam o federalismo, o mais comum é a federação?, à qual Watts (2013, p. 25) atribui as seguintes características estruturais: (i) no mínimo duas ordens de governo (central e subcentral); (ii) distribuição constitucional de autoridade legislativa e executiva e alocação específica de recursos para cada ordem; (iii) garantia de participação das unidades constituintes nos processos decisórios do governo central, geralmente através de uma segunda câmara legislativa; (iv) Constituição escrita e rígida, não unilateralmente emendável e com regras específicas para alteração; (v) corte capaz de decidir conflitos intergovernamentais; (vi) mecanismos e instituiçôes que facilitam a colaboração intergovernamental nas áreas em que as competências são compartilhadas ou sobrepostas.

A origem de uma federação geralmente é explicada por questóes históricas, geográficas ou territoriais, como nos casos de Argentina, Brasil, México, Alemanha e Estados Unidos, em que a extensão do território seria uma das razóes da escolha do modelo federativo; ou por questóes culturais, étnicas e religiosas que produzem tensóes, impelindo à necessidade de inclusão e/ou autonomia, como nos casos da Bélgica, Bósnia e Herzegovina, Canadá, Etiópia e Índia. Já a formação da federação pode seguir três movimentos: a agregação de unidades anteriormente separadas, como

8 The semifederal category includes three democracies that Robert Dahl has called "sociological federal" (cited in Verba 1967,126): Belgium, the Netherlands and Israel. The central governments of these countries have long recognized, heavily subsidized, and delegated power to private associations with important semipublic functions, especially in the fields of education, culture, and health care, established by the major religious and ideological groups in these societies. Because these groups are not geographically concentrated, sociological federalism deviates from Riker's criterion that the component units of a federation should be regional in nature. (LIJPHART, 2012, p.180) 
nos Estados Unidos e na Suíça; a devolução de autonomia de um Estado unitário para unidades constituintes, como na Bélgica, na Alemanha e na Nigéria; ou a combinação desses fluxos, como ocorreu na Índia, no Canadá e na Malásia. Desses movimentos surgem tensôes: no primeiro caso, visando à autonomia das partes constituintes; no segundo, no sentido da retenção de poder pelo governo central originário; no terceiro, uma cadeia de concessóes entre os entes constitutivos precisa ser celebrada em prol da unidade do conjunto (WATTS, 2013, p. 27).

A diversidade de algumas federaçóes pode justificar a distribuição assimétrica de poderes em favor de determinadas unidades, por razóes geográficas, populacionais, sociais, culturais ou econômicas. Watts (2013) pondera que, embora isso possa parecer uma fonte de conflitos internos, incorporar alguma assimetria é uma forma de acomodar tensóes existentes entre as unidades.

Ainda sob a ótica das assimetrias internas, uma "vantagem" da maioria dos países estudados por Samuels e Snyder (2001) é a representação desproporcional dos distritos eleitorais nas casas legislativas. Pelas regras eleitorais, as unidades subnacionais mais populosas desses países - geralmente, as economicamente mais desenvolvidas - têm um número relativamente menor de cadeiras legislativas do que as unidades menos populosas - e, em geral, menos desenvolvidas. A representação desproporcional tende a ser maior em Estados federais, mas existe também em Estados unitários.

Nesse sentido, as características institucionais dos sistemas federais causariam um impacto independente na política e nas políticas públicas, ou seja, suas instituiçóes serviriam para corrigir assimetrias subjacentes - territoriais, populacionais, econômicas, étnicas etc., confirmando-as ou corrigindo-as (GIBSON, CALVO; FALLETI, 2003). Entre essas instituiçóes, podemos citar o bicameralismo e a divisão de cadeiras em cada casa, as prerrogativas constitucionais dos governos subcentrais e central, e a estruturação do sistema de partidos.

Conforme Kauchakje (2017), quando se trata de federaçóes, a explicação aceita na literatura para a representação distrital desproporcional é que esta foi estruturada como forma de proteção e norma compensatória para as unidades em desvantagem econômica e potencial desvantagem política. Essa estruturação teria o objetivo de agrupar unidades autônomas e assimétricas, sendo, portanto, uma estratégia para integrar as unidades e estabilizar a comunidade política na origem da formação de Estados. Em alguns contextos isso pode ser interpretado como uma concessão dos setores urbanos para a elite rural (DRAGU; RODDEN, 2011; LEE, 2000; RODDEN, 2002). Nessa linha, a sobrerrepresentação legislativa de unidades menos populosas e de baixo desempenho econômico seria "um mecanismo compensatório entre unidades desiguais, proporcionando alavancagem política a províncias ou estados frágeis" diante da influência política, econômica ou demográfica das unidades dominantes, resultado que poderia ser positivo para a estabilidade e a integridade territorial dos sistemas federais “com assimetrias econômicas e demográficas significativas entre suas unidades subnacionais" (GIBSON, CALVO; FALLETI, 2003, p. 100). Em suma, a sobrerrepresentação seria uma forma de equalizar unidades regionalmente desiguais e evitar o favorecimento de determinadas unidades em detrimento de outras. Nesse sentido, vários estudos apontam que unidades sobrerrepresentadas recebem mais recursos do que os distritos sub-representados (ANSOLABEHERE et al., 2002; ARRETCHE; RODDEN, 2004; DRAGU; RODDEN, 2011; KAUCHAKJE, 2017).

O bicameralismo representaria a garantia de que uma casa atenderia aos anseios 
democráticos (casa baixa, parlamento), e a outra aos interesses territoriais (casa alta, senado). Em tese, esse desenho provocaria, seja na primeira ou na segunda câmara, a representação dos interesses agregados dos distritos das(os) legisladores. Para o caso brasileiro, no entanto, Ricci (2003) e Ricci e Lemos (2004) demonstraram que a maior parte de leis votadas no período por eles estudado tratava de matéria nacional, a menor parcela cabendo a projetos com características distributivistas e paroquiais. Não cabe aqui abordar o debate entre a vertente que apresenta evidências sobre a prática de pork barrel e o caráter local/distributivo das produçóes do Legislativo nacional (AMES, 1995; BARON; FEREJOHN, 1989; PEREIRA; MUELLER, 2002) e a vertente que discorda dessa ênfase distributivista, demonstrando que as coalizóes são disciplinadas pelas regras que orientam a relação entre Executivo e Legislativo e a votação legislativa. Quando se trata do Brasil, autores dessa última vertente destacam a proeminência do poder Executivo e o papel dos líderes partidários no que diz respeito à iniciativa e às votaçôes no geral, e à iniciativa e execução da lei orçamentária em particular (ARRETCHE; RODDEN, 2004; CHEIBUB; FIGUEIREDO; LIMONGI, 2009; FIGUEIREDO; LIMONGI, 2002).

Apesar das distinçôes mais marcadas na perspectiva teórica, no federalismo as instituiçōes - que, devido à propagação da "ideia federal" e das "soluçóes federais", passaram a ser incorporadas também por sistemas unitários - têm como principal objetivo promover um equilíbrio entre rigidez e flexibilidade, que se evidencia na contraposição entre shared rule e self rule, relacionando-se com duas forças simultâneas que se opóem: uma força que impulsiona a união das partes em direçáo a um propósito comum, e outra que impele as unidades constituintes a buscarem autonomia em razão de outros propósitos (WATTS, 2005, p. 322-349). Curiosamente, os mesmos motivos que conduzem à formação de algumas federaçóes e à promoção de regras compartilhadas, como a necessidade de "acomodar" diversidades históricas, étnicas, linguísticas, culturais, populacionais ou geográficas, podem provocar o seu enfraquecimento em razão da busca por maior autonomia.

A partir das diferenças e aproximaçóes entre os diferentes desenhos pelos quais os Estados se constituem, e das implicaçóes que as características de cada modelo produzem, passamos a observar especificidades dos processos de espraiamento de políticas que podem estar ligadas à divisão de poder entre governo central e unidades subcentrais, às relaçóes intergovernamentais e ao modo como se estabelecem essas relaçóes.

\section{Modelagem de políticas em cenários de divisão de poder}

Uma das características atribuídas aos Estados federais é a capacidade de inovar das unidades subcentrais. Essa capacidade decorreria de sua autonomia política, ou seja, seu poder para formular e implementar políticas públicas, independentemente da concordância do governo central. Contrariamente, os Estados unitários são pensados como tendo uma maior uniformidade de políticas públicas, e mesmo havendo divisóes administrativas locais, estas não teriam capacidade decisória para inovar ou teriam capacidade limitada. Tanto em Estados unitários como em Estados federais, uma medida a ser considerada é o grau de descentralização efetiva a partir do governo central em direção aos governos subnacionais.

A transferência e difusão podem incidir sobre a formulação de políticas públicas. Tais processos ocorrem tanto entre Estados como dentro de Estados. Nosso objetivo é analisar este último contexto - políticas transferidas ou difundidas no interior dos Estados -, considerando aspectos ligados à divisão de 
poder e às relaçôes intergovernamentais entre unidades centrais e subcentrais. Dentro dessa perspectiva, observamos a possibilidade de indução ou coerção pelo governo central, mecanismos que importam na transferência ou difusão de políticas entre os entes subnacionais (como imitação, competição ou cooperaçáo) e elementos que facilitam ou dificultam o espraiamento nos diversos cenários de divisão de poder.

A fim de conferir maior abrangência ao nosso estudo, utilizamos recursos da revisão sistemática da literatura para identificar, nas bases de artigos científicos Scopus e Scielo ${ }^{10}$, estudos com análises empíricas que trouxessem dados significativos para nossa análise. Tais recursos foram utilizados para evitar o viés de seleção dos artigos, alcançando estudos que tratam de contextos diversos daqueles mais citados pela literatura.

Para refinar nossa busca, além da seleção de palavras-chave ${ }^{11}$, utilizamos os critérios "conteúdo" (critério de seleção/inclusão na amostra) e "qualidade dos periódicos" (critério de manutenção/não exclusão da amostra). O critério "conteúdo" foi utilizado para identificar os estudos do recorte: artigos com estudos empíricos sobre transferência, difusão ou aprendizado de políticas entre unidades constitutivas de sistemas federais ou unitários, centralizados e descentralizados. Nesta primeira etapa identificamos 291 artigos. Com a leitura dos respectivos resumos e a exclusão de resultados falso-positivos quanto ao conteúdo, a amostra ficou em 164 artigos. Após essa seleção, os artigos foram submetidos ao critério de não exclusão, sendo mantidos na amostra os artigos publicados em periódicos qualificados nos estratos $\mathrm{A} 1$ ou $\mathrm{A} 2$ do ranking de periódicos Qualis, da Coordenação de Aperfeiçoamento de Pessoal de Nível Superior (Capes), e/ou nos estratos Q1 e Q2, do ranking de periódicos Scimago Journal \& Country Rank (SJR) ${ }^{12}$.

Desse total, selecionamos uma amostra parcial aleatória de 33 estudos empíricos ${ }^{13}$, dos quais 13 foram excluídos porque, após a leitura integral, verificamos que os casos narrados não tinham aderência a nossa pesquisa. Os estudo abordam o policy making em nível subnacional, discutindo o federalismo bottom-up, isto é, a dispersão de competências do governo central para os governos subnacionais ou a ação

10 Limitamos a busca a artigos científicos publicados em periódicos.

11 Termos de busca utlizados: i) para o Scopus 'bottom-up' AND federalism, 'top-down' AND federalism, federalism AND 'subnational governments', 'policy diffusion' AND federalism, 'policy transfer' AND federalism, 'policy diffusion' AND 'local government', 'policy diffusion' AND 'central government', 'policy diffusion' AND 'bottomup', 'policy diffusion' AND 'top-down', 'policy transfer' AND 'bottom-up', 'policy transfer' AND 'top-down', 'top-down' AND 'intergovernmental relations', 'policy diffusion' AND 'intergovernmental relations', 'policy transfer' AND 'intergovernmental relations'; ii) para o Scielo, 'transferência de políticas' AND 'governo local', 'transferência de políticas' AND 'governo central', 'difusão de políticas' AND 'governo local', 'difusão de políticas' AND 'governo central', 'difusão de políticas' AND federalismo, 'transferência políticas' AND federalismo, 'transferência de políticas' AND 'bottom-up', 'transferência de políticas', AND 'top-down', 'difusão de políticas' AND 'bottom-up', 'difusão de políticas', AND 'top-down'.

12 Tendo em vista os critérios adotados acerca do conteúdo dos artigos e da qualidade dos periódicos, não estabelecemos critérios de exclusão com relação às áreas de avaliação dos periódicos, ainda que a maioria seja proveniente de revistas/journals avaliados na grande área 'Ciências Humanas', área de avaliação 'Ciência Política e Relações Internacionais'; grande área 'Ciências Sociais Aplicadas', área de avaliação 'Administração Pública e de Empresas'; grande área 'Planejamento Urbano e Regional', área de avaliação 'Planejamento Urbano e Regional'; 'grande área 'Multidisciplinar', área de avaliação 'Interdisciplinar' (para o Qualis-CAPES) e área Ciências Sociais, categorias 'Ciência Política e Relaçôes Internacionais', 'Sociologia e Ciência Política', 'Administração Pública' e 'Planejamento e Desenvolvimento’ (para o Scimago).

13 Os artigos selecionados aparecem nas referências, em separado. 
proativa dos governos locais em áreas em que as competências não estáo claramente definidas (ABRAMS; WOLLSTEIN; DAVIS, 2018; DERTHICK, 2007; LUTSEY; SPERLING, 2008; ROSENTHAL et al., 2015), e não discutem casos de difusão de políticas. Assim, os resultados parciais apresentados neste artigo reúnem as conclusóes apresentadas em 20 estudos empíricos sobre transferência, difusão e aprendizado de políticas entre unidades constituintes (central e subcentrais) de sistemas políticos unitários e federais, centralizados e descentralizados. Apresentamos os resultados de nossa análise no Quadro 1.

O objetivo metodológico de nossa pesquisa é reunir, identificar e confrontar argumentos e achados que demonstrem a interface entre a análise das estruturas intergovernamentais e de divisão de poder e o intercâmbio de políticas públicas entre entes de um sistema político. Conforme apontamos na introdução, alguns estudos sobre difusão e transferência de políticas têm considerado a divisão de poder entre governo central e unidades subcentrais como variável de análise (GILARDI; FUGLISTER, 2008; GRAY, 1973; MCCANN; SHIPAN; VOLDEN, 2015; SHIPAN; VOLDEN, 2006; WALKER, 1969), mas sem avaliar isoladamente ou em profundidade sua relevância. Além disso, as conclusóes desses estudos permanecem dispersas na literatura sobre o tema, sem que haja uma análise sistemática dos diversos achados no campo. Nossa pesquisa e este artigo pretendem contribuir nesse aspecto.

A importância de se analisar o policy making em contextos de divisão de poder entre governo central e unidades subnacionais surge porque, em tais cenários, políticas criadas em um nível de governo repercutem nos demais níveis (BAYBECK; BERRY; SIEGEL, 2011). Nesse sentido, vários dos estudos por nós analisados confirmam que unidades subnacionais funcionam como laboratórios (COÊLHO, CAVALCANTE;
TURGEON, 2016; JANS et al., 2016; Lundin, Öberg; Josefsson, 2015; SHIPAN; VOLDEN, 2006; SUGIYAMA, 2011) que permitem a inovação e a experimentação em políticas que, posteriormente, poderão se difundir para outras unidades (GODWIN; SCHROEDEL, 2000; KRENJOVA; RAUDLA, 2018; Lundin, Öberg; Josefsson, 2015; SUGIYAMA, 2011). As pesquisas destacam a importância de estudar a modelagem de políticas em Estados federais (COÊLHO; CAVALCANTE; TURGEON, 2016; NUTLEY et al., 2012; SHIPAN; VOLDEN, 2006; SUGIYAMA, 2011) e em Estados unitários que garantem alguma autonomia às unidades constituintes (LIU; LI, 2016; Lundin; Öberg; Josefsson, 2015; MA, 2017; KRENJOVA; RAUDLA, 2018). Além disso, os dados sinalizam que essas dinâmicas ocorrem em sistemas federais, unitários, centralizados e descentralizados.

Com relação aos reflexos mútuos entre estruturas de divisão de poder entre governo central e unidades subcentrais e processos de transferência, difusão ou aprendizado de políticas, parte da literatura analisada entende que os arranjos federativos ou unitários interferem ou favorecem o espraiamento (BOYD, 2017; GODWIN; SCHROEDEL, 2000; KIM, 2013; LIU; LI, 2016; Lundin, Öberg; Josefsson, 2015), enquanto outros admitem o efeito inverso (COÊLHO, CAVALCANTE; TURGEON, 2016; KIM, 2013; SHIPAN; VOLDEN, 2006). Na primeira corrente estáo aqueles que entendem que incentivos institucionais da divisão vertical de poderes interferem positivamente no aprendizado, difusão ou transferência por concederem às unidades subnacionais autonomia para inovar em políticas e por possibilitarem a cooperação, a integração e o fluxo de informaçóes entre as unidades (BOYD, 2017; LIU; LI, 2016; Lundin, Öberg; Josefsson, 2015). Na segunda, os que admitem que a busca por modelos de políticas provoca interaçôes entre governos de mesmo nível e de níveis diferentes, o que, a depender do 
ambiente político, pode alterar as relaçôes entre eles e interferir no sistema de políticas de um país (COÊLHO, CAVALCANTE; TURGEON, 2016; KIM, 2013; SHIPAN; VOLDEN, 2006).

Analisar processos de transferência, difusão ou aprendizado pressupóe observar razōes e elementos que influenciam a decisão de uma unidade de seguir modelos já implementados. Nesse sentido, a existência de unidades políticas que podem servir de referência para políticas cria uma heurística cognitiva para os tomadores de decisão, que, devido à sua racionalidade limitada e à incapacidade de acessar todas as soluçóes e ferramentas políticas possíveis para um problema, voltam-se para localidades similares, vizinhas ou com iniciativas exitosas, para observar como elas vêm reagindo a problemas semelhantes (KIM, 2013; Lundin; Öberg; Josefsson, 2015; SHIPAN; VOLDEN, 2006;) e antecipando decisões das demais unidades (BAYBECK; BERRY; SIEGEL, 2011). Isso, no entanto, não se aplicaria a todos os contextos, pois segundo os estudos de Liu e $\mathrm{Li}$ (2016) e Ma (2017), que tratam da difusão de políticas dentro de um sistema unitário e autoritário, nestes cenários a competição entre as unidades a fim de serem bem avaliadas por seus superiores impulsiona mais à inovação do que à emulação de políticas. A opção de servir de modelo pode decorrer de uma decisão racional e deliberada de uma unidade, no sentido de competir com as demais, de adquirir ou manter reputação de inovadora perante seus pares ou o governo central ou de exercer influência (Krenjova; Raudla, 2018; Lundin, Öberg; Josefsson, 2015; MA, 2017).

Para Rye et al. (2011), transferência, difusão ou aprendizado entre unidades de um sistema político, unitário ou federal, centralizado ou descentralizado, pode provocar policy integration vertical, horizontal ou interna (entre órgãos da estrutura governamental de mesmas ou diferentes áreas). Com relação a esses fluxos, Shipan e Volden (2008, p. 841) desenvolveram uma tipologia para a difusão de políticas em sistemas federais. Para os autores, a depender da relação existente entre os polos emissores e receptores da política, a difusão pode ser: horizontal, entre unidades de mesma ordem (município a município, estado a estado, província a província ${ }^{14}$ ); bottom-up (a partir das unidades subcentrais para os níveis superiores); ou top-down (do governo central para as unidades subcentrais). Em casos como o do Brasil, em que a divisão vertical de poder se dá em três níveis, a modalidade bottom-up pode se verificar dos estados para o governo central, e a top-down pode ocorrer a partir dos estados para as municipalidades. Pela proximidade teórica e empírica entre os conceitos de transferência, difusão e aprendizado, entendemos que a tipologia citada pode ser aplicada aos três casos. Do mesmo modo, utilizaremos a mesma classificação para Estados unitários que contenham divisôes administrativas verticais internas, pois interessa-nos o espraiamento da política entre as unidades de um sistema político, independente do arranjo de divisão de poder adotado.

A difusão de políticas de transferência monetária na América Latina é um processo que retrata como ocorrem estes movimentos. Tais políticas foram inicialmente criadas em municipalidades brasileiras e difundiram-se entre elas (difusão horizontal). Depois, a adoção do modelo em nível local influenciou a criação de políticas similares pelo governo central brasileiro (difusão bottom-up), e seu êxito colaborou com seu espraiamento para outros países (difusão horizontal internacional), incentivado por diretrizes e prescriçôes oriundas de organizaçóes como Unesco, ONU e Banco Mundial. A demonstração desse processo e

14 Entendemos que a difusão horizontal pode ocorrer também no nível internacional, entre países. 
seus efeitos pode ser observada no estudo de Sugiyama $(2011)^{15}$.

A modelagem ou difusão horizontal de políticas é a modalidade mais explorada nas pesquisas, tanto entre países como entre unidades subnacionais, com destaque aos estudos sobre a difusão de inovaçôes entre as unidades federativas dos Estados Unidos (BAYBECK, BERRY; SIEGEL, 2011; BUTLER et al. 2017; GODWIN; SCHROEDEL, 2000; KOSKI, 2010; MCCANN, SHIPAN; VOLDEN, 2015; SHIPAN; VOLDEN, 2006). Essa modalidade de difusão resulta da competição econômica entre unidades (cria-se a política para obter lucros ou para não perder investimentos); da pressão social (quando indivíduos sabem do sucesso de políticas em jurisdiçóes vizinhas e passam a pressionar a sua unidade para implementá-las também); e da busca por seguir modelos exitosos (JANS et al., 2016; Lundin, Öberg; Josefsson, 2015; SHIPAN; VOLDEN, 2006). A difusão horizontal tende a ter um alcance mais amplo, atingindo várias unidades, podendo chegar até mesmo à convergência, como foi verificado nos estudos de Shipan e Volden (2006), Sugiyama (2008, 2011), McCann, Shipan e Volden (2015) e Coêlho, Cavalcante e Turgeon (2016).

A difusão vertical a partir das unidades subnacionais em direção ao governo central, ou difusão bottom-up, sugere a influência da adoção de políticas em nível local na adoção de políticas pelo governo regional ou central. A adoção de leis em nível local/subnacional pode influenciar a adoção por unidades verticalmente "superiores", além de permitir que governos de níveis superiores se inspirem em políticas exitosas já implementadas localmente, das quais receberão créditos posteriormente (MCCANN, SHIPAN; VOLDEN, 2015;
SHIPAN; VOLDEN, 2006; SUGIYAMA 2008; SUGIYAMA, 2011).

Como mencionado, na difusão de políticas de transferência de renda no Brasil, o efeito bottom-up foi observado, considerando que a política, inicialmente implementada nos municípios em meados de 2001, se estendeu ao nível federal, coincidindo com um período de disponibilidade de recursos (através da criação do Fundo de Combate e Erradicação da Pobreza), com a influência de atores com experiência no modelo local e com a competição dentro do PSDB entre Paulo Renato Souza e José Serra ${ }^{16}$ pela candidatura à presidência da República (SUGIYAMA, 2011).

Outro tipo de difusão vertical se dirige do governo central para as unidades subnacionais (difusão top-down). Nesses cenários, mesmo o debate de temas de interesse geral, em nível nacional, repercute em nível local e regional. Isso ocorre de duas formas: unidades inovadoras se antecipam ao governo central criando suas próprias leis ou políticas, enquanto outras adiam sua ação até que políticas nacionais sejam aprovadas (MCCANN, SHIPAN; VOLDEN, 2015). Mesmo sem criar obrigatoriedade, a proeminência do tema na agenda do governo central emite um sinal às unidades subnacionais de que há espaço de ação (KIM, 2013; LIU; LI, 2016; MCCANN; SHIPAN; VOLDEN, 2015), e esta ação é mais provável se houver retorno eleitoral pela formulação da política (BAYBECK, BERRY; SIEGEL, 2011; COÊLHO, CAVALCANTE; TURGEON, 2016; MCCANN, SHIPAN; VOLDEN, 2015; SUGIYAMA, 2008; SUGIYAMA, 2011) ou incentivos financeiros do governo central (SHIPAN; VOLDEN, 2006; SUGIYAMA, 2008; SUGIYAMA, 2011).

15 Estudo de Silva (2015) e Silva, Kauchakje e Delazari (2017) analisam este mesmo processo, mas na perspectiva da difusão horizontal internacional, entre países da América Latina e Caribe.

16 Ambos os nomes eram atrelados ao anterior Bolsa Alimentação. 
Percebe-se que o governo central interfere nas políticas locais também de forma matizada, difundindo ideias e conteúdo de políticas através de audiências, projetos de lei (MCCANN; SHIPAN; VOLDEN, 2015) e estabelecimento de metas (KIM, 2013; KOSKI, 2010; LIU; LI, 2016; NUTLEY et al., 2012). Em alguns contextos, a falta de interferência do governo central no fornecimento de recursos materiais ou na determinação de metas mais claras quanto à política (KIM, 2013; KRENJOVA; RAUDLA, 2018) é apontada como um obstáculo à adoção da política difundida, o que denota a dependência que algumas unidades têm do governo central, mesmo em contextos de descentralização administrativa, em que possuem autonomia para implementar a política.

Outro aspecto relevante nos estudos sobre transferência, difusão e aprendizado de políticas diz respeito aos mecanismos pelos quais estes processos ocorrem, o que faz com que uma política implementada em uma jurisdiçáo seja replicada em outra, o que leva uma unidade a seguir um modelo implementado por outra unidade (BRAUN; GILARDI, 2006; DOBBINS, SIMMONS; GARRETT, 2007; SHIPAN; VOLDEN, 2008).

Os autores se concentram em quatro mecanismos mais frequentes: aprendizado, imitação, competição e coerção. $\mathrm{O}$ aprendizado ocorre quando os policymakers, diante da necessidade de formular uma política, retiram liçôes de experiências de outras unidades (foco na ação), e baseiam sua decisão neste conteúdo; a imitação seria uma busca de reconhecimento ou legitimidade, a tentativa de copiar determinada jurisdição ou governo para se parecer com ele (foco no ator); já a competiçáo seria uma decisão estratégica, decorrente de políticas anteriores que provocam efeitos econômicos ou sociais para outra(s) unidade(s); e, por fim, a coerção, em contextos internos, decorreria de pressóes políticas ou incentivos financeiros vinculantes por unidades de maior nível na estrutura de governo a fim de forçar as unidades inferiores a adotarem certa política (COÊLHO, 2016; DOBBINS, SIMMONS; GARRETT, 2007; SHIPAN; VOLDEN 2008;).

Gonnet (2016, p. 77) afirma que "a distinção entre um mecanismo e outro é difusa” e a análise empírica aponta nessa direção; alguns mecanismos não são facilmente identificáveis, outros não se enquadram na divisão corrente na literatura. Nos casos analisados em nosso estudo, observamos os seguintes mecanismos: competiçâo econômica, social (açẫo decorrente de spillovers econômicos ou sociais de outras políticas) e por reputação (intenção de adquirir proeminência, legitimidade ou influenciar os demais); socialização por cooperação (quando as unidades agem de forma independente mas possuem canais de socializaçáo pelos quais a informação é transferida) ou por aprendizado (quando as unidades optam racionalmente por aprender com outras unidades) e pressōes verticais (indução ou coerção de níveis superiores do governo para adoção da política).

Interessaram-nos também os fatores que interferem nas dinâmicas de transferência, difusão e aprendizado. Elementos como similaridade cultural, econômica e ideológica, reputação do primeiro adotante, interferência de atores externos, recompensas eleitorais e custos de adoção, entre outros, podem criar incentivos positivos ou negativos para replicar modelos preexistentes (BENNETT, 1991; DUNLOP, 2009; GILARDI, 2010; KINGDON, 1984; WALKER, 1969). Redes de políticas e associaçôes intergovernamentais (como associações de prefeitos), empreendedores de políticas, grupos de pressão, mídia e organizações internacionais frequentemente participam desses processos.

A similaridade é apontada em diversos estudos como facilitadora da transferência, difusão ou aprendizado, pois, na busca por soluções políticas, é comum que os policymakers atentem para semelhanças culturais, econômicas, 
sociais ou ideológicas. Nesse aspecto, foram apontados elementos como idioma/dialeto comum, cultura política, antecedentes históricos, composição da sociedade e identidade religiosa ou política (BAYBECK, BERRY; SIEGEL, 2011; COÊLHO, CAVALCANTE; TURGEON, 2016; KIM, 2013; MA, 2017; NUTLEY et al., 2012; SHIPAN; VOLDEN, 2006). Quanto à identidade ideológica, o estudo de Lundin, Öberg e Josefsson (2015), que analisa a difusão de políticas na Suécia, apontou que esse fator não foi relevante, o que, segundo os autores, pode decorrer das características internas e da cultura política do país, já que o mesmo resultado foi verificado em outras pesquisas desenvolvidas nos países nórdicos. Já nos estudos de Sugiyama (2008 e 2011) sobre a difusão de políticas de transferência monetária entre as municipalidades do Brasil, a autora demonstra que prefeitos ligados ao Partido dos Trabalhadores e ao Partido da Social Democracia Brasileira implementaram tais políticas. Ou seja, aqui, mais forte do que o fator ideológico foi a busca por recompensas eleitorais, pois, conforme Samuels (2003) e Samuels e Mainwaring (2004), uma característica estreitamente ligada às instituiçôes federativas nacionais é que as eleiçóes para prefeito no Brasil, especialmente nas capitais, são importantes degraus na construção de carreiras políticas e oportunidades de captaçáo de capital eleitoral para próximas candidaturas.

O elemento "competitividade" é bastante relevante nos cenários analisados, tanto em Estados federais como em unitários. Nos primeiros, ela aparece como reação a consequências econômicas ou sociais da adoção prévia de uma política por outra unidade, como queda na arrecadaçẫo ou perda de investimentos (BAYBECK,
BERRY; SIEGEL, 2011; MCCANN; SHIPAN; VOLDEN, 2015; SHIPAN; VOLDEN, 2006). Já nos Estados unitários, pode estar associada à busca de reconhecimento e prestígio pelas unidades subnacionais e seus administradores, em contextos em que as avaliaçōes de desempenho pelo governo central são importantes, pois delas depende a progressão de carreira dos oficiais (LIU; LI, 2016; MA, 2017), bem como em cenários em que as unidades subcentrais buscam alcançar maior autonomia e independência em relação ao governo central (BRETON; FRASCHINI, 2003) ou se firmar perante as demais como unidades inovadoras, que náo seguem modelos pré-formatados (NUTLEY et al. 2012).

Outro fator que aparece em inúmeros estudos é a ação de atores externos. Redes de políticas, associaçóes de prefeitos, grupos de pressão e empreendedores de políticas são elencados como elementos fundamentais para o aprendizado, difusão ou transferência. Ao se dirigirem a atores-chave (como grandes municipalidades, unidades com boa reputação ou com influência sobre as demais), os atores externos otimizam os resultados de sua açấo e maximizam o número de adotantes de uma política, especialmente quando eventos focais ou circunstâncias inesperadas aumentam a pressão pela mudança política ${ }^{17}$ (GODWIN; SCHROEDEL, 2000). Redes e associaçôes profissionais constituem canais de interação horizontal, de socialização de informaçōes, ideias e influência (JANS et al. 2016; SHIPAN; VOLDEN, 2006). Além disso, algumas políticas de alta complexidade precisam de intermediários entre o corpo técnico da formulação da política e os responsáveis por sua adoção e implementação,

17 O estudo de Godwin e Schroedel, sobre políticas de desarmamento nos Estados Unidos, demonstra que ocorrências com grande número de vítimas mobilizaram a opiniáo pública em favor daquelas políticas, e estas situaçôes foram usadas pelos policy entrepreneurs como argumento para intensificar sua açáo e pressionar os governos para adotarem medidas de controle ou proibição de acesso às armas. 
papel desempenhado por profissionais como os knowledge brokers, que agem para traduzir e comunicar aspectos técnicos da política que defendem (KOSKI, 2010).

\section{Quadro 1}

\section{Características identificadas nos estudos empíricos ${ }^{18}$}

\begin{tabular}{|c|c|c|}
\hline Variável & & Resultados \\
\hline \multirow{4}{*}{$\begin{array}{c}\text { Estrutura } \\
\text { interna }\end{array}$} & $\begin{array}{c}\text { Federal } \\
\text { centralizado }\end{array}$ & $\begin{array}{l}\text { Coêlho Cavalcante e Turgeon (2016), Rye et al. (2011), Sugiyama (2008), } \\
\text { Sugiyama (2011) }\end{array}$ \\
\hline & $\begin{array}{c}\text { Federal } \\
\text { descentralizado }\end{array}$ & $\begin{array}{l}\text { Baybeck, Berry e Siegel (2011), Rye et al. (2011), Shipan e Volden (2006), Godwin } \\
\text { e Schroedel (2000), Koski (2010), McCann, Shipan e Volden (2015), Boyd (2017), } \\
\text { Butler et al. (2015) }\end{array}$ \\
\hline & $\begin{array}{l}\text { Unitário } \\
\text { centralizado }\end{array}$ & Rye et al. (2011), Kim (2013), Krenjova e Raudla (2018), Liu e Li (2016), Ma (2017) \\
\hline & $\begin{array}{c}\text { Unitário } \\
\text { descentralizado }\end{array}$ & $\begin{array}{l}\text { Rye et al. (2011), Nutley et al. (2012), Jans et al. (2016), Lundin, Öberg e Josefsson } \\
\text { (2015), Wolman e Page (2002), Breton e Fraschini (2003) }\end{array}$ \\
\hline \multirow[t]{3}{*}{ Modalidade } & Difusăo & $\begin{array}{l}\text { Coêlho, Cavalcante e Turgeon (2016), Baybeck, Berry e Siegel (2011), Rye et al. (2011), } \\
\text { Shipan e Volden (2006), Godwin e Schroedel (2000), Jans et al. (2016), Kim (2013), } \\
\text { Koski (2010), Krenjova e Raudla (2018), Liu e Li (2016), Lundin, Öberg e } \\
\text { Josefsson (2015), Butler et al. (2015), Sugiyama (2008), Sugiyama (2011), McCann, } \\
\text { Shipan e Volden (2015) }\end{array}$ \\
\hline & Transferência & Rye et al. (2011), Nutley et al. (2012), Wolman e Page (2002), Boyd (2017) \\
\hline & Aprendizado & $\begin{array}{l}\text { Nutley et al. (2012), Koski (2010), Krenjova e Raudla (2018), Lundin, Öberg e } \\
\text { Josefsson (2015), Ma (2017), Butler et al. (2015) }\end{array}$ \\
\hline \multirow[t]{3}{*}{ Sentido } & Horizontal & $\begin{array}{l}\text { Ma (2017), Lundin, Öberg e Josefsson (2015), Liu e Li (2016), Krenjova } \\
\text { e Raudla (2018), Koski (2010), Kim (2013), Jans et al. (2016), Godwin e } \\
\text { Schroedel (2000), Shipan e Volden (2006), Nutley et al. (2012), Rye et al. (2011), } \\
\text { Baybeck, Berry e Siegel (2011), Coêlho,Cavalcante e Turgeon (2016), Wolman e } \\
\text { Page (2002), Boyd (2017), Sugiyama (2008) e Sugiyama (2011), McCann, Shipan e } \\
\text { Volden (2015), Breton e Fraschini (2003) }\end{array}$ \\
\hline & Bottom-up & $\begin{array}{l}\text { Shipan e Volden (2006), Sugiyama (2008), Sugiyama (2011), McCann, Shipan e } \\
\text { Volden (2015) }\end{array}$ \\
\hline & Top-down & $\begin{array}{l}\text { Liu e Li (2016), Koski (2010), Kim (2013), Jans et al. (2016), Godwin e } \\
\text { Schroedel (2000), Shipan e Volden (2006), Nutley et al. (2012), Rye et al. (2011), } \\
\text { Coêlho, Cavalcante e Turgeon (2016), McCann, Shipan e Volden (2015) }\end{array}$ \\
\hline $\begin{array}{c}\text { Fatores } \\
\text { intervenientes }\end{array}$ & $\begin{array}{l}\text { Favoráveis } \\
\text { à adoçăo }\end{array}$ & $\begin{array}{l}\text { - } \text { similaridade cultural (Kim, 2013; Ma, 2017; Nutley et al., 2012); demográfica } \\
\text { (Lundin, Öberg e Josefsson,2015); orçamentária (Lundin, Öberg e Josefsson, 2015); } \\
\text { ideológica (Coêlho,Cavalcante e Turgeon, 2016; Shipan e Volden, 2006; } \\
\text { Nutley et al., 2012; Baybeck, Berry e Siegel, 2011) } \\
\text { - proximidade geográfica (Shipan e Volden, 2006; Lundin, Öberg e Josefsson, 2015; } \\
\text { Baybeck, Berry e Siegel, 2011; Wolman e Page, 2002) } \\
\text { - reputaçáo do primeiro adotante (Godwin e Schroedel, 2000; Krenjova e Raudla, } \\
\text { 2018; Ma, 2017; Boyd, 2017; Sugiyama, 2011) } \\
\text { - novidade da política (Coêlho, Cavalcante } \\
\text { e Turgeon, 2016; Shipan e Volden, 2006; Godwin e Schroedel, 2000) } \\
\text { - sucesso anterior da política (Shipan e Volden, 2006; Jans et al., 2016; Lundin, Öberg } \\
\text { e Josefsson, 2015; Butler et al., 2015) } \\
\text { - compatibilidade da política (Godwin e Schroedel, 2000; Krenjova e Raudla, 2018; } \\
\text { Rye et al., 2011) } \\
\text { - path dependence (Rye et al., 2011; Nutley et al., 2012; Shipan e Volden, 2006) }\end{array}$ \\
\hline
\end{tabular}

(Continua)

18 Alguns casos aparecem em mais de uma categoria por tratarem de situaçóes que envolvem diferentes unidades, com fluxos independentes de modelagem de políticas, e sob efeitos diversos e não excludentes. 


\section{Quadro 1 - continuação}

\begin{tabular}{|c|c|c|}
\hline Variável & & Resultados \\
\hline $\begin{array}{c}\text { Fatores } \\
\text { intervenientes }\end{array}$ & $\begin{array}{l}\text { Favoráveis } \\
\text { à adoção }\end{array}$ & $\begin{array}{l}\text { - vantagens econômicas da adoção (Baybeck, Berry e Siegel, 2011; Boyd, 2017; } \\
\text { Wolman e Page, 2002; Koski, 2010) } \\
\text { - pressão social (Shipan e Volden, 2006; Kim, 2013) } \\
\text { - incentivos eleitorais (Shipan e Volden, 2006; Baybeck, Berry e Siegel, 2011; } \\
\text { Sugiyama, 2011) } \\
\text { - recursos institucionais, orçamentários, sociais, humanos (Shipan e Volden, 2006; } \\
\text { Jans et al., 2016; Rye et al., 2011; Krenjova e Raudla, 2018; Kim, 2013; Nutley } \\
\text { et al., 2012; Baybeck, Berry e Siegel, 2011; Coêlho,Cavalcante e Turgeon, 2016; } \\
\text { Sugiyama, 2008; Sugiyama, 2011; McCann, Shipan e Volden, 2015; Breton e } \\
\text { Fraschini, 2003) } \\
\text { - demandas internas (Kim, 2013; Ma, 2017; Koski, 2010; Jans et al. (2016) } \\
\text { - características populacionais (Coêlho, Cavalcante } \\
\text { e Turgeon, 2016; Baybeck, Berry e Siegel, 2011; Shipan e Volden, 2006; Godwin e } \\
\text { Schroedel, 2000) } \\
\text { - características do adotante (Jans et al., 2016; Sugiyama, 2008; Butler et al., 2015; } \\
\text { Godwin e Schroedel, 2000) } \\
\text { - atores externos: grupos de pressão (Shipan e Volden, 2006; Godwin e Schroedel, } \\
\text { 2000; McCann, Shipan e Volden, 2015), redes de políticas (Kim, 2013; } \\
\text { Lundin, Öberg e Josefsson, 2015; Godwin e Schroedel, 2000; Jans et al., 2016; } \\
\text { Sugiyama, 2008; Sugiyama, 2011; Coêlho,Cavalcante e Turgeon, 2016), mídia } \\
\text { (Kim, 2013; Krenjova e Raudla, 2018), policy entrepreneurs (Shipan e Volden, 2006; } \\
\text { Godwin e Schroedel, 2000; Krenjova e Raudla, 2018; Ma, 2017; Koski, 2010; Jans } \\
\text { et al., 2016; McCann, Shipan e Volden, 2015; Sugiyama, 2008; Sugiyama, 2011), } \\
\text { organizaçōes internacionais (Sugiyama, 2011) }\end{array}$ \\
\hline $\begin{array}{c}\text { Fatores } \\
\text { intervenientes }\end{array}$ & $\begin{array}{l}\text { Desfavoráveis } \\
\text { à adoçăoo }\end{array}$ & $\begin{array}{l}\text { - custo da política: econômico (Baybeck, Berry e Siegel, 2011; Shipan e Volden, 2006; } \\
\text { Krenjova e Raudla, 2018), político (Koski, 2010; Baybeck, Berry e Siegel, 2011) } \\
\text { - complexidade da política (Jans et al., 2016; Krenjova e Raudla, 2018; Koski, 2010) } \\
\text { - preempção (Shipan e Volden, 2006; Godwin e Schroedel, 2000) } \\
\text { - incompatibilidade ideológica, cultural, econômica (Rye et al., 2011; } \\
\text { Nutley et al., 2012; Kim, 2013) } \\
\text { - falta de induçấo do governo central (Kim, 2013; Krenjova e Raudla, 2018) } \\
\text { - competiçáo (Rye et al., 2011; Nutley et al., 2012; Shipan e Volden, 2006) } \\
\text { - características populacionais (Kim, 2013; Coêlho, Cavalcante e Turgeon, 2016) }\end{array}$ \\
\hline \multirow{3}{*}{ Mecanismo } & Competição & $\begin{array}{l}\text { - econômica e/ou social (Shipan e Volden, 2006; Ma, 2017; Liu e Li, 2016; Krenjova } \\
\text { e Raudla, 2018; Koski, 2010; Kim, 2013; Rye et al., 2011; Baybeck, Berry e } \\
\text { Siegel, 2011; Nutley et al., 2012; McCann, Shipan e Volden, 2015; Wolman e } \\
\text { Page, 2002; Boyd, 2017; Breton e Fraschini, 2003; Sugiyama, 2011) } \\
\text { - por reputaçáo/imitaçáo (Liu e Li, 2016; Krenjova e Raudla, 2018; Koski, 2010; } \\
\text { Kim, 2013) }\end{array}$ \\
\hline & Socialização & $\begin{array}{l}\text { - cooperaçáo (Lundin, Öberg e Josefsson, 2015; Rye et al., 2011; Jans et al., 2016; } \\
\text { Sugiyama, 2008; Coêlho, Cavalcante e Turgeon, 2016) } \\
\text { - aprendizado (Lundin, Öberg e Josefsson, 2015; Liu e Li, 2016; Krenjova e } \\
\text { Raudla, 2018; Koski, 2010; Godwin e Schroedel, 2000; Rye et al., 2011; Wolman } \\
\text { e Page, 2002; Boyd, 2017; Butler et al., 2015) }\end{array}$ \\
\hline & $\begin{array}{l}\text { Pressōes } \\
\text { verticais }\end{array}$ & $\begin{array}{l}\text { Shipan e Volden, 2006; Jans et al., 2016; Kim, 2013; Koski, 2010; Nutley et al., 2012; } \\
\text { Baybeck, Berry e Siegel, 2011; Coêlho, Cavalcante e Turgeon, 2016; Sugiyama, 2008; } \\
\text { Sugiyama, 2011) }\end{array}$ \\
\hline
\end{tabular}

Fonte: Elaboração própria a partir de dados da pesquisa. 
A relação entre arranjos de divisão vertical de poder e o espraiamento de políticas é demonstrada pela estrutura de repartição de autoridade e competências entre as unidades constituintes - como nos casos dos estudos no Canadá, Holanda, Itália e Suécia (BOYD, 2017; BRETON; FRASCHINI, 2003; JANS et al. 2016; Lundin, Öberg; Josefsson, 2015); pela estrutura político-partidária ou pelas regras eleitorais (COÊLHO, CAVALCANTE; TURGEON, 2016; SUGIYAMA, 2008; SUGIYAMA, 2011); e pela proatividade ou demora na ação do governo central (MCCANN; SHIPAN; VOLDEN, 2015; SHIPAN; VOLDEN, 2006).

As características identificadas nos estudos empíricos que observamos demonstram que elementos das estruturas federativas, mesmo quando presentes em Estados unitários, e dinâmicas de difusão, transferência e aprendizado de políticas podem ser conjugados, por apresentarem reflexos mútuos. De um lado, e entre outras características inerentes a esses contextos, a divisão de poder e de competência favorece a inovação das unidades constituintes; ao mesmo tempo, tornam a replicação de políticas uma possibilidade a ser considerada pelos decisores locais; além disso, o maior ou menor controle do governo central pode dificultar ou favorecer o espraiamento de políticas entre unidades subnacionais, de acordo com os incentivos de que essas unidades precisam para implementar políticas. De outro lado, processos de aprendizado, difusão e transferência criam canais de comunicação, interação, troca e influência, gerando dinâmicas de cooperação, coordenação, competição e coerção que podem interferir na estrutura de divisão vertical de poder ou nas relaçóes intergovernamentais entre as unidades, ainda que de forma matizada.

\section{Considerações finais}

A formulação de políticas públicas é um processo permeável aos interesses e à cultura política dos policymakers e à influência de grupos de pressão, partidos políticos, mídia, comunidades epistêmicas, empreendedores de políticas e diferentes atores que transitam dentro e fora do governo, e a modelos de políticas já implementados por outras jurisdiçóes. Neste artigo, discutimos, especificamente, a relação entre a opção por um sistema político unitário ou federal, centralizado ou descentralizado, na formulação de políticas pelo governo central e pelas unidades subcentrais, com ênfase em processos de transferência, difusão e aprendizado de políticas entre as unidades constituintes destes sistemas.

Ambientes de escalonamento de níveis decisórios, sejam eles federaçôes propriamente ditas ou Estados unitários descentralizados, são cenários propícios ao trânsito de informação, conteúdo, boas práticas e modelos de políticas. Muito além da convivência dentro de um mesmo sistema legislativo, que por si só favorece a padronização de políticas, outros elementos acentuados por estruturas federativas ou "federalizadas" intensificam a migração de políticas públicas entre as unidades constituintes.

Constatamos que a atuação de redes que incluem tecnocratas, empreendedores de políticas e oficiais do governo é relevante na socialização de informação, padróes, rankings e modelos, acelerando a difusão de políticas entre as unidades. Contribuem também a competição entre as unidades, o impulso para inovar e a identificação ideológica ou partidária. Mas esse último elemento pode ser desconsiderado quando incentivos eleitorais são postos em jogo, o que mobiliza atores situados em diferentes posiçóes do espectro político-partidário a se engajarem na difusão de políticas capazes de produzir capital eleitoral e agradar eleitores.

Outro fator a ser considerado é a dinâmica profissional, tanto de burocratas quanto de representantes eleitos. Indivíduos 
inicialmente situados em determinada escala de governo, ao se deslocarem para outras esferas governamentais, carregam o conhecimento anteriormente adquirido sobre políticas e passam a influenciar o desenvolvimento de políticas similares nas novas jurisdiçôes. $\mathrm{O}$ grau de descentralização também interfere na modelagem de políticas; nos casos onde a descentralização da capacidade decisória é maior, cabendo às unidades constituintes subnacionais a tomada de decisão, a possibilidade de difusão entre estas unidades também aumenta, e ganham destaque as unidades precursoras ou inovadoras, liderando dinâmicas de bandwagoning.

Os fatores que apontamos servem para reforçar nosso argumento principal sobre a importância de analisar os efeitos de incentivos institucionais na modelagem ou espraiamento de políticas entre unidades constituintes.
Particularmente, os estudos analisados apontam que o arranjo de divisão de poder e de autoridade no âmbito das políticas públicas é uma variável a ser considerada para entender tanto os processos de difusão, transferência e aprendizado, como a própria formulação da política em unidades subcentrais.

Concluímos que analisar a influência da divisão de poder na modelagem de políticas em suas diferentes modalidades é uma abordagem promissora, pouco explorada na pesquisa no campo. Os estudos sobre transferência, difusão e aprendizado dão menor ênfase aos aspectos relacionados à divisão de poder, não alcançando uma discussão sistemática sobre modelagem de políticas públicas em Estados unitários e federais. Este artigo é uma tentativa inicial de preencher essa lacuna, e em seus desdobramentos aprofundaremos nossa análise e o debate aqui apresentado.

\section{Referências}

ACHARYA, A. How ideas spread: whose norms matter? Norm localization and institutional change in Asian regionalism. International Organization, Cambridge, v. 58, n. 2, p. 239-275, 2004.

AMES, B. Electoral rules, constituency pressures, and pork barrel: bases of voting in the Brazilian Congress. The Journal of Politics, Chicago, v. 57, n. 2, p. 324-343, 1995.

Os entraves da democracia no Brasil. São Paulo: FGV Editora, 2003.

ANSOLABEHERE, S. et al. Equal votes, equal money: court-ordered redistricting and public expenditures in the American states. American Political Science Review, Cambridge, v. 96, n. 4, p. 767-777, 2002.

ARRETCHE, M. Demos-constraining or demos-enabling federalism? Political institutions and policy change in Brazil. Journal of Politics in Latin America, Hamburg, v. 5, n. 2, p. 133-150, 2013.

Federalism, bicameralism, and institutional change: general trends and one case study. Brazilian Political

Science Review, Rio de Janeiro, v. 4, n. 2, p. 10-31, 2010.

ARRETCHE, M., RODDEN, J. Política distributiva na Federação: estratégias eleitorais, barganhas legislativas e coalizóes de governo. Dados, Rio de Janeiro, v. 47, n. 3, p. 549-576, 2004. 
BALDI, B. Beyond the federal-unitary dichotomy. Berkeley: Institute of Governmental Studies, 1999. Disponível em: <http://escholarship.org/uc/item/05b607ng>. Acesso em: 29 ago. 2017.

BARON, D.; FEREJOHN, J. Bargaining in legislatures. American Political Science Review, Cambridge, v. 83, n. 4, p. 1181-1206, 1989.

BENNETT, C. What is policy convergence and what causes it? British Journal of Political Science, Cambridge, v. 21, n. 2, p. 215-233, 1991.

BERRY, F.; BERRY, W. State lottery adoptions as policy innovations: an event history analysis. American Political Science Review, Cambridge, v. 84, n. 2, p. 395-415, 1990.

BRADY, B.; CURTIN, C. Big brothers big sisters comes to Ireland: a case study in policy transfer. Children and Youth Services Review, Amsterdam, v. 34, n. 8, p. 1433-1439, 2012.

BRAUN, D.; GILARDI, F. Taking 'Galton's problem’seriously: towards a theory of policy diffusion. Journal of Theoretical Politics, Thousand Oaks, v. 18, n. 3, p. 298-322, 2006.

BRAY, D. J.; TAYLOR, M. A. P.; SCRAFTON, D. Transport policy in Australia: evolution, learning and policy transfer. Transport Policy, Amsterdam, v. 18, n. 3, p. 522-532, 2011.

CHEIBUB, J.; FIGUEIREDO, A.; LIMONGI, F. Partidos políticos e governadores como determinantes do comportamento legislativo na câmara dos deputados, 1988-2006. Dados, Rio de Janeiro, v. 52, n. 2, 2009.

COÊLHO, D. Mecanismos políticos e institucionais da difusão de políticas. In: FARIA, C. A.; COÊLHO, D.; SILVA, S. (Orgs.). Difusão de politicas públicas. São Paulo: Ed. UFABC, 2016. p. 35-64.

. Political competition and the diffusion of conditional cash transfers in Brazil. Brazilian Political Science Review, Rio de Janeiro, v. 6, n. 2, p. 56-87, 2012.

COOK, I. Mobilizing urban policies: the policy transfer of US business improvement districts to England and Wales. Urban Studies, Thousand Oaks, v. 45, n. 4, p. 773-795, 2008.

DIMAGGIO, P.; POWELL, W. The iron cage revisited: collective rationality and institutional isomorphism in organizational fields. American Sociological Review, Thousand Oaks, v. 48, n. 2, p. 147-160, 1983.

DOBBINS, F.; SIMMONS, B.; GARRETT, G. The global diffusion of public policies: social construction, coercion, competition, or learning? Annual Review of Sociology, Palo Alto, v. 33, p. 449-472, 2007.

DOLOWITZ, D.; MARSH, D. Learning from abroad: the role of policy transfer in contemporary policy making. Governance, Montreal, v. 13, n. 1, p. 5-23, 2000.

DRAGU, T.; RODDEN, J. Representation and redistribution in federations. Proceedings of the National Academy of Sciences, Washington, DC, v. 108, n. 21, p. 8601-8604, 2011. 
DUNLOP, C. Policy transfer as learning: capturing variation in what decision-makers learn from epistemic communities. Policy Studies, Hoboken, v. 30, n. 2, p. 289-311, 2009.

DYE, T. Party and policy in the states. The Journal of Politics, Chicago, v. 46, n. 4, p. 1097-1116, 1984.

ELAZAR, D. Exploring federalism. Tuscaloosa: University of Alabama Press, 1987.

EVANS, M. At the interface between theory and practice, policy transfer and lesson drawing. Public Administration, Hoboken, v. 84, n. 2, p. 479-489, 2006.

EVANS, M.; DAVIES, J. Understanding policy transfer: a multi-level, multi-disciplinary perspective. Public Administration, Hoboken, v. 77, n. 2, p. 361-385, 1999.

EVANS, P.; RUESCHEMEYER, D.; SKOCPOL, T. Bringing the State back in. Cambridge: University Press, 1985.

FIGUEIREDO, A; LIMONGI, F. Incentivos eleitorais, partidos e política orçamentária. Dados, Rio de Janeiro, v. 45, n. 2, p. 303-344, 2002.

GERRING, J.; THACKER, S.; MORENO, C. Centripetal democratic governance: a theory and global inquiry. American Political Science Review, Cambridge, v. 99, n. 4, p. 567-581, 2005.

GIBSON, E.; CALVO, E.; FALLETI, T. Federalismo realocativo: sobrerepresentação legislativa e gastos públicos no hemisfério ocidental. Opiniāo Pública, Campinas, v. 9, n. 1, p. 98-123, 2003.

GILARDI, F. Who learns from what in policy diffusion processes? American Journal of Political Science, Bloomington, v. 54, n. 3, p. 650-666, 2010.

GILARDI, F.; FUGLISTER, K. Empirical modeling of policy diffusion in federal states: the dyadic approach. Swiss Political Science Review, Zurich, v. 14, n. 3, p. 413-450, 2008.

GOLDFINCH, S. Rituals of reform, policy transfer, and the national university corporation reforms of Japan. Governance, Montreal, v. 19, n. 4, p. 585-604, 2006.

GONNET, C. Mecanismos y actores en los procesos de difusión: discusión a partir de los casos de los programas de transferencia condicionada en América Latina. In: FARIA, C. A.; COÊLHO, D.; SILVA, S. (Orgs.) Difusão de politicas públicas. São Paulo: Ed. UFABC, 2016. p. 65-100.

The role of international organizations in a policy diffusion process: preliminary discussion about the Conditional Cash Transfers programs in Latin America. In: CHILEAN CONGRESS OF POLITICAL SCIENCE, 10., 2012, Madrid. Anais... Santiago: Chilean Political Science Association, 2012.

GRAY, V. Innovation in the States: a diffusion study. American Political Science Review, Cambridge, v. 67, n. 4, p. 1174-1185, 1973. 
HAAS, P. Introduction: epistemic communities and international policy coordination. International Organization, Cambridge, v. 46, n. 1, p. 1-35, 1992.

HOCHMANN, G. Aprendizado e difusão na constituição de políticas: a previdência social e seus técnicos. Revista Brasileira de Ciências Sociais, São Paulo, v. 3, n. 7, p. 84-98, 1988.

HOLZINGER, K.; KNILL, C. Causes and conditions of cross-national policy convergence. Journal of European Public Policy, Abingdon, v. 12, n. 5, p. 775-796, 2005.

HOSPERS, G-J.; BEUGELSDIJK, S. Regional cluster policies: learning by comparing? Kyklos, Hoboken, v. 55, n. 3 , p. 381-402, 2002.

HULME, R. Policy transfer and the internationalisation of social policy. Social Policy and Society, Thousand Oaks, v. 4, n. 4, p. 417-425, 2005.

JACOBS, K.; BARNETT, P. Policy transfer and policy learning: a study of the $1991 \mathrm{New}$ Zealand Health Services Taskforce. Governance, Montreal, v. 13, n. 2, p. 185-213, 2000.

KAUCHAKJE, S. Representação distrital e coalizóes legislativas: o impacto da sobrerrepresentação nas votaçôes no Congresso Brasileiro. Tese (Doutorado) - Universidade Federal de São Carlos, São Carlos, 2017.

KAUCHAKJE, S., SILVA, E. Z.; PESSALI, H. Social programs of big impact and middle-range theories: diffusion and transfer process in Latin America. In: IPSA CONGRESS, 23., 2014, Montreal. Anais... Montreal: IPSA, 2014.

KINGDON, J. Agendas, alternatives, and public policies. Boston: Little, Brown, 1984.

LASSWELL, H; KAPLAN, A. Power and society. New Haven: Yale University, 1950.

LEE, F. Senate representation and coalition building in distributive politics. American Political Science Review, Cambridge, v. 94, n. 1, p. 59-72, 2000.

LIJPHART, A. Patterns of democracy: government forms and performance in thirty six countries. 2. ed. New Haven: Yale University Press, 2012.

LOWI, T. The state in politics: the relation between policy and administration. In: Regulatory policy and the social sciences. Berkeley: University of California Press, 1985. p. 67-105

MAJONE, G. Cross-national sources of regulatory policymaking in Europe and the United States. Journal of Public Policy, Cambridge, v. 11, n. 1, p. 79-106, 1991.

MARKS, G.; HOOGHE, L.; SCHAKEL, A. Measuring regional authority. Regional and Federal Studies, Abingdon, v. 18, n. 2-3, p. 111-121, 2008. 
MARSDEN, G.; STEAD, D. Policy transfer and learning in the field of transport: a review of concepts and evidence. Transport Policy, Amsterdam, v. 18, n. 3, p. 492-500, 2011.

MINTROM, M. Policy entrepreneurs and the diffusion of innovation. American Journal of Political Science, Bloomington, v. 41, n. 3, p. 738-770, 1997.

MINTROM, M.; VERGARI, S. Policy networks and innovation diffusion: the case of State education reforms. The Journal of Politics, Chicago, v. 60, n. 1, p. 126-148, 1998.

NEWBURN, T. Atlantic crossings: "policy transfer" and crime control in the USA and Britain. Punishment \& Society, Thousand Oaks, v. 4, n. 2, p. 165-194, 2002.

ONGARO, E. The dynamics of devolution processes in legalistic countries: organizational change in the Italian public sector. Public Administration, Hoboken, v. 84, n. 3, p. 737-770, 2006.

PALERMO, F.; KÖSSLER, K. Comparative federalism: constitutional arrangements and case law. Portland: Hart Publishing, 2017.

PEREIRA, C.; MUELLER, B. Comportamento estratégico em presidencialismo de coalizão: as relaçôes entre Executivo e Legislativo na elaboração do orçamento brasileiro. Dados, Rio de Janeiro, v. 45, n. 2, p. 265-301, 2002.

PRZEWORSKI, A. Sustainable democracy. Cambridge: Cambridge University Press, 1995.

RADAELLI, C. Policy transfer in the European Union: institutional isomorphism as a source of legitimacy. Governance, Montreal, v. 13, n. 1, p. 25-43, 2000.

RICCI, P. O conteúdo da produçấo legislativa brasileira: leis nacionais ou políticas paroquiais?. Dados, v. 46, n. 4, p. 699-734, 2003.

RICCI, P.; LEMOS, L. Produção legislativa e preferências eleitorais na Comissão de Agricultura e Política Rural da Câmara dos Deputados. Revista Brasileira de Ciências Sociais, v. 19, n. 55, p. 107-129, 2004.

RODDEN, J. Federalismo e descentralização em perspectiva comparada: sobre significados e medidas. Revista de Sociologia e Politica, Curitiba, v. 24, p. 9-27, 2005.

Strength in Numbers? Representation and redistribution in the European Union. European Union Politics, Thousand Oaks, v. 3, n. 2, p. 151-175, 2002.

ROGERS, E. Diffusion of innovations. New York: Free Press, 2003.SAMUELS, D. Ambition, federalism, and legislative politics in Brazil. Cambridge: Cambridge University Press, 2003.

SAMUELS, D.; MAINWARING, S. Federalism, constraints on the central government, and economic reform in democratic Brazil. Federalism and democracy in Latin America. Notre Dame (IN): Kellogg Institute, 2004. 
SAMUELS, D.; SNYDER, R. The value of a vote: malapportionment in comparative perspective. British Journal of Political Science, Cambridge, v. 31, n. 4, p. 651-671, 2001.

SHIPAN, C.; VOLDEN, C. The mechanisms of policy diffusion. American Journal of Political Science, Bloomington, v. 52, n. 4 , p. $840-857,2008$.

SILVA, E. Z. Formulaçôes globais e políticas locais: a difusão de políticas de transferência monetária na América Latina e Caribe. Dissertação (Mestrado) - Pontifícia Universidade Católica do Paraná, Curitiba, 2015.

SILVA, E. Z.; KAUCHAKJE, S.; DELAZARI, L. La política de persuasión del Banco Mundial en sus informes de desarrollo mundial (1990-2015). América Latina Hoy, Salamanca, v. 75, p. 75-100, 2017.

SKOCPOL, T.; AMENTA, E. States and social policies. Annual Review of Sociology, Palo Alto, v. 12, p. 131-157, 1986.

SOUZA, C. Políticas públicas: questóes temáticas e de pesquisa. Caderno CRH, Salvador, v. 16, n. 39, p. 11-24, 2006.

STEPAN, A. Brazil's decentralized federalism: bringing government closer to the citizens? Daedalus, Cambridge, v. 129, n. 2, p. 145-169, 2000.

. Para uma nova análise comparativa do federalismo e da democracia: federaçóes que restringem ou ampliam o poder do demos. Dados, Rio de Janeiro, v. 42, n. 2, 1999.

STONE, D. Learning lessons and transferring policy across time, space and disciplines. Politics, Hoboken, v. 19, n. 1, p. 51-59, 1999.

. Non-governmental policy transfer: the strategies of independent policy institutes. Governance, Montreal, v. 13, n. 1 , p. 45-70, 2000.

TSEBELIS, G. Jogos ocultos: escolha racional no campo da política comparada. São Paulo: Edusp, 1998.

VOLDEN, C. States as policy laboratories: emulating success in the children's health insurance program. American Journal of Political Science, Bloomington, v. 50, n. 2, p. 294-312, 2006.

WALKER, J. The diffusion of innovations among the American states. American Political Science Review, Cambridge, v. 63 , n. 3, p. $880-899,1969$.

WAMPLER, B. When does participatory democracy deepen the quality of democracy? Lessons from Brazil. Comparative Politics, New York, v. 41, n. 1, p. 61-81, 2008.

WATTS, R. L. A comparative perspective on asymmetry in federations. Kingston (CA): Queen's University, 2005.

Typologies of federalism. In: LOUGHLIN, J; KINCAID, J.; SWENDEN, W. (Eds.) Routledge handbook of regionalism and federalism. London: Routledge, 2013. p. 18-33. 
WEYLAND, K. Bounded rationality and policy diffusion: social sector reform in Latin America. Princeton: Princeton University Press, 2007.

\section{Artigos selecionados pela revisão sistemática da literatura}

ABRAMS, J.; WOLLSTEIN, K.; DAVIS, E. State lines, fire lines, and lines of authority: rangeland fire management and bottom-up cooperative federalism. Land Use Policy, Amsterdam, v. 75, p. 252-259, 2018.

BAYBECK, B.; BERRY, W.; SIEGEL, D. A strategic theory of policy diffusion via intergovernmental competition. The Journal of Politics, Chicago, v. 73, n. 1, p. 232-247, 2011.

BOYD, B. Working together on climate change: policy transfer and convergence in four Canadian provinces. Publius, Oxford, v. 47, n. 4, p. 546-571, 2017.

BRETON, A; FRASCHINI, A. Vertical competition in unitary states: the case of Italy. Public Choice, New York, v. 114 , n. 1-2, p. 57-77, 2003.

BUTLER, D. et al. Ideology, learning, and policy diffusion: experimental evidence. American Journal of Political Science, Bloomington, v. 61, n. 1, p. 37-49, 2017.

COÊLHO, D; CAVALCANTE, P; TURGEON, M. Mecanismos de difusão de políticas sociais no Brasil: uma análise do Programa Saúde da Família. Revista de Sociologia e Política, Curitiba, v. 24, n. 58, p. 145-165, 2016.

COLINO, C. Constitutional change without constitutional reform: Spanish federalism and the revision of Catalonia's statute of autonomy. Publius, Oxford, v. 39, n. 2, p. 262-288, 2009.

DERTHICK, M. Where federalism didn't fail. Public Administration, Hoboken, v. 67, n. 1, p. 36-47, 2007.

GAMKHAR, S.; PICKERILL, M. The state of American federalism 2011-2012: a fend for yourself and activist form of bottom-up federalism. Publius, Oxford, v. 42, n. 3, p. 357-386, 2012.

GODWIN, M.; SCHROEDEL, J. Policy diffusion and strategies for promoting policy change: evidence from California local gun control ordinances. Policy Studies, Hoboken, v. 28, n. 4, p. 760-776, 2000.

JANS, W. et al. Mandatory innovation in a decentralised system: the adoption of an e-government innovation in Dutch municipalities. Acta Politica, Basingstoke, v. 51, n. 1, p. 36-60, 2016.

KIM, D-E. Local government policy diffusion in a decentralised system: childbirth support policy in South Korea. Local Government Studies, Abingdon, v. 39, n. 4, p. 582-599, 2013.

KOSKI, C. Greening America’s skylines: the diffusion of low-salience policies. Policy Studies, Hoboken, v. 38, n. 1, p. 93-117, 2010. 
KRENJOVA, J.; RAUDLA, R. Policy diffusion at the local level: participatory budgeting in Estonia. Urban Affairs Review, Thousand Oaks, v. 54, n. 2, p. 419-447, 2018.

LIU, W.; LI, W. Divergence and convergence in the diffusion of performance management in China. Public Performance \& Management Review, Abingdon, v. 39, n. 3, p. 630-654, 2016.

LUNDIN, M.; ÖBERG, P.; JOSEFSSON, C. Learning from success: are successful governments role models? Public Administration, Hoboken, v. 93, n. 3, p. 733-752, 2015.

LUTSEY, N; SPERLING, D. America's bottom-up climate change mitigation policy. Energy Policy, Amsterdam, v. 36, n. 2, p. 673-685, 2008.

MA, L. Site visits, policy learning, and the diffusion of policy innovation: evidence from public bicycle programs in China. Journal of Chinese Political Science, New York, v. 22, n. 4, p. 581-599, 2017.

MCCANN, P.; SHIPAN, C.; VOLDEN, C. Top-down federalism: state policy responses to national government discussions. Publius, Oxford, v. 45, n. 1, p. 495-525, 2015.

MCGUIRE, M. Intergovernmental management: a view from the bottom. Public Administration Review, Hoboken, v. 66 , n. 5 , p. $677-679,2006$.

NGUYEN, X-T. Dynamic federalism and patent law reform. Indiana Law Journal, Bloomingtron, v. 85, 449, 2010.

NUTLEY, S. et al. Policy transfer and convergence within the UK: the case of local government performance improvement regimes. Policy \& Politics, Bristol, v. 40, n. 2, p. 193-209, 2012.

PALLEY, H. Canadian abortion policy: national policy and the impact of federalism and political implementation on access to services. Publius, Oxford, v. 36, n. 4, p. 565-586, 2006.

PICKERILL, M.; BOWLING, C. Polarized parties, politics, and policies: fragmented federalism in 2013-2014. Publius, Oxford, v. 44, n. 3, p. 369-398, 2014.

ROSENTHAL, C. et al. Beyond (and within) city limits: climate policy in an intergovernmental system. Review of Policy Research, Hoboken, v. 32, n. 5, p. 538-555, 2015.

RYE, T. et al. First steps towards cross-national transfer in integrating mobility management and land use planning in the EU and Switzerland. Transport Policy, Amsterdam, v. 18, n. 3, p. 533-543, 2011.

SELLERS, J. Federalism and metropolitan governance in cross-national perspective: the case of urban sprawl. Environment and Planning, Thousand Oaks, v. 20, n. 1, p. 95-112, 2002.

SHIPAN, C.; VOLDEN, C. Bottom-up federalism: the diffusion of antismoking policies from US cities to states. American Journal of Political Science, Bloomington, v. 50, n. 4, p. 825-843, 2006. 
SMULLEN, A. Not centralisation but decentralised integration through Australia's National Mental Health Policy. Australian Journal of Public Administration, Hoboken, v. 75, n. 3, p. 280-290, 2016.

SOLARI, S. Constitutions for local collective action and institutional interdependence. Constitutional Political Economy, New York, v. 15, n. 1, p. 89-107, 2004.

SUGIYAMA, N. B. Bottom-up policy diffusion: national emulation of a conditional cash transfer program in Brazil. Publius, Oxford, v. 42, n. 1, p. 25-51, 2011.

. Theories of policy diffusion: social sector reform in Brazil. Comparative Political Studies, Thousand Oaks, v. 41, n. 2, p. 193-216, 2008.

WOLMAN, H.; PAGE, E. Policy transfer among local governments: an information-theory approach. Governance, Montreal, v. 15, n. 4, p. 577-501, 2002.

\section{Resumo}

\section{Divisão de autoridade em Estados unitários e federais e difusão de políticas}

No artigo analisamos a relação entre divisão vertical de poder dentro de um sistema político e transferência, difusão ou aprendizado de políticas entre as unidades constituintes. Sob essa ótica, discutimos fluxos verticais e horizontais de disseminação de políticas, formas de indução ou coerção pelo governo central e mecanismos como imitação, competição ou cooperação entre unidades subnacionais de estados unitários ou federais que interferem no espraiamento de políticas. Como estratégia metodológica, usamos dados e resultados de pesquisas publicadas em periódicos científicos a fim de identificar características e padróes distintivos da transferência, da difusão ou do aprendizado de políticas relacionados com a estrutura de divisâo de poder entre governo central e unidades subcentrais. Concluímos que elementos como forma de repartiçấo de competências, regras eleitorais, padrōes de carreira na burocracia governamental, competição entre as unidades e grau de descentralização influenciam a transferência, difusão ou aprendizado de políticas em sistemas unitários ou federais.

Palavras-chave: Estados Unitários, Estados Federais, Divisão de Poder; Transferência de Políticas Públicas; Difusão de Políticas Públicas.

\section{Abstract}

\section{Division of authority in unitary and federal States and policy diffusion}

In this article we analyze the relationship between vertical division of power whithin a political system and policy transfer, policy diffusion or policy learning between constituent units. From this perspective, we discuss vertical and horizontal flows of policy dissemination, forms of induction or coercion by central government, and mechanisms such as imitation, competition or cooperation between subnational units of unitary or federal states that interfere on policy spreading. As a methodological strategy, we use data and research results published in scientific journals to identify distinguishing features and patterns of policy transfer, policy diffusion or policy learning related to the structure of division of power between central government and subcentral units. We conclude that elements such as distribution of competencies, electoral rules, career patterns in government bureaucracy, competition between units and degree of decentralization influence policy transfer, policy diffusion or policy learning in unitary or federal systems.

Keywords: Unitary State; Federal State; Division of Power; Policy Transfer; Policy Diffusion. 


\section{Résumé}

\section{Division de l'autorité en États unitaires et fédéraux et diffusion des politiques}

Dans cet article, nous analysons la relation entre la division verticale du pouvoir au sein d'un système politique et le transfert, la diffusion ou l'apprentissage des politiques entre les unités constitutives. Dans cette perspective, nous discutons des flux verticaux et horizontaux de diffusion des politiques, des formes d'induction ou de coercition par le gouvernement central et des mécanismes tels que l'imitation, la concurrence ou la coopération entre les unités infranationales des États unitaires ou fédéraux. En tant que stratégie méthodologique, nous utilisons des données et des résultats de recherche publiés dans des revues scientifiques pour identifier les caractéristiques et les modèles distinctifs de transfert, de diffusion ou d'apprentissage politique liés à la structure de la division du pouvoir entre les unités centrales et subcentrales. Nous concluons que des éléments tels que la répartition des compétences, les règles électorales, les carrières dans la bureaucratie gouvernementale, la concurrence entre les unités et le degré de décentralisation influencent le transfert, la diffusion ou l'apprentissage des politiques dans les systèmes unitaires ou fédéraux.

Mots-clés: États Unitaires; États Federaux; Division de l'Autorité; Transfert des Politiques; Diffusion des Politiques. 